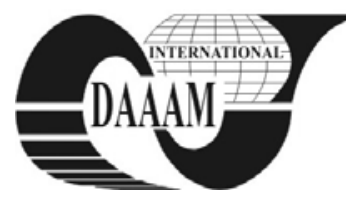

\title{
OPTIMIZED SOLUTION FOR THE WITHDRAWAL PLANT OF A STEEL VERTICAL CONTINUOUS CASTING INSTALLATIONS BY CHANGING THE ROLLER'S SURFACE
}

\author{
VELA, I[on]; TUFOI, M[arius]; AMARIEI, D[aniel]; VELA, D[aniel] \& CIORBA, I[on]
}

\begin{abstract}
In this work is presented an optimization solution of correcting withdrawal rollers to the withdrawal of the semifinished products of steel to vertical continuous casting plant of steel for increase the productivity of continuous casting process. To optimize rollers was used statistical calculations applied to experimental measurements obtained directly from the withdrawal of blanks and using modern techniques, such as: CAD (Computer Aided Design) and CAE (Computer Aided Engineering) for design, modeling and optimization of rollers. Also, has been used finite element method (FEM) for static and dynamic simulations, the behavior of withdrawal-straightening rolls in continuous casting process for determining stress, strain and displacement that occur in this process concerning the semi-finished products withdrawn. The studies aim to improve the process of withdrawal of the semi continuous castings with vertical curvilinear wire of steel for improve the quality of semi-finished products.
\end{abstract}

Key words: continuous casting, rollers, withdrawal, optimizing, $C A D$

\section{INTRODUCTION}

Continuous casting of metals is a process for obtaining metal blanks directly from molten metal in the form of wires, billets, blooms, tubes of different sizes. The process of continuous casting consists in introducing molten metal into a crystallizer (mold) externally cooled with water. In crystallizer occurs the partial solidification (at surface) of the metal. This, under metal-static pressure, left the crystallizer, and is taken by a withdrawing mechanism equipped with pinch rolls that helps to extract blank, see fig.1.

The blank is then subjected to a secondary cooling in order to complete solidification. Then there is the blank cutting to length desired by the customer, and evacuation of the production flow, quality control department towards. Continuous casting of metals and especially for steel is a technique increasingly used both nationally and globally, because it has major advantages compared with conventional casting of steel profiles (Shapiro et al., 2008). Thus, upgrading and optimization of continuous casting process, including installation of withdrawal of the semi-finished profiles of metals is an intense focus of research in the field for improve the quality of semi-finished products (Tufoi et al., 2009).

\section{PROBLEM FORMULATION}

The authors propose an optimization of the withdrawal rolls of continuous casting plant of low-alloy steel used to obtain pipe. Installation is a vertical continuous casting plant with curvilinear wire and equipped with four cages for withdrawal. Layout is shown in fig. 2.

The continuous casting machine is designed for continuous casting of round billets with a diameter up to $\varnothing 350 \mathrm{~mm}$ and maximum size $400 \times 250 \mathrm{~mm}$ slabs (Tufoi et al., 2010). This machine of continuous casting and the withdrawal cages in function are shown in fig. 2 .

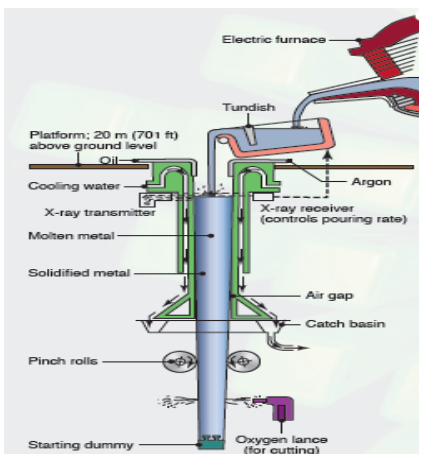

Fig. 1. Vertical continuous casting of steel

Vertical continuous casting machine characteristics studied are:

-Melting pot - 100 tons of molten alloy steel;

-Number of threads -3;

-Radius wire- 13, $000 \mathrm{~mm}$;

-Tundish capacity - 17 tons;

-Crystallizer-mold vertical design of $\mathrm{Cu}-\mathrm{Ag}$;

-Jet protection between distributor and mold- immersed tube;

-Maximum speed casting- 2.5m/min;

-Secondary cooling- water jets.

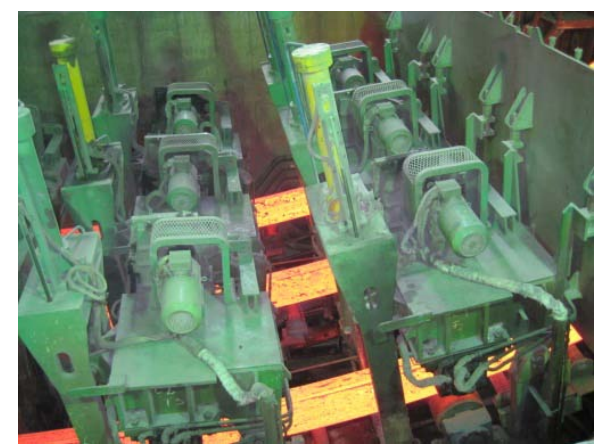

Fig. 2. Vertical continuous casting machine- withdrawal cages

In this installation of continuous casting ingot size change is necessary to change the withdrawal rolls which are processed according to each profile dimension withdrawn. This change is necessary only for round profiles, each roll of different radius withdrawal being processed (Marta et al., 2010). This is detailed in fig.3. Continuous casting machine described above is used to obtain the round profile with the following diameters: $\varnothing 177 \mathrm{~mm}, \varnothing 250 \mathrm{~mm}, \varnothing 280 \mathrm{~mm}$ and Ø350mm.

Continuous casting machine described above is used to obtain the round profile with the following diameters: $\varnothing 177 \mathrm{~mm}, \varnothing 250 \mathrm{~mm}, \varnothing 280 \mathrm{~mm}$ and $\varnothing 350 \mathrm{~mm}$. When changing the size and profile is needed to replacing retired withdrawal rollers for each size separately. This has several disadvantages: 
- long times ( six hours) required to change the twentyfour metal roll with an average weight of $500 \mathrm{~kg}$ each;

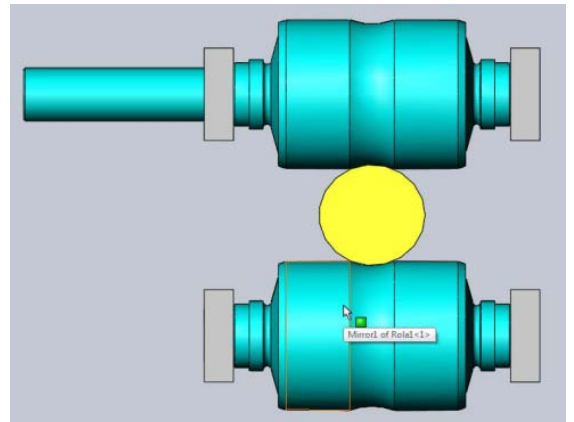

Fig. 3. Lower and upper withdrawal rollers with single radius

-for changing rollers is required adjustments and calibrations after their installation in stands of withdrawal;

- need large space for storage and transfer of rollers.

To remove this disadvantage, the authors propose the design new geometry for optimization of a pair of rollers with multiple radiuses (four) capable of withdrawing all four sizes of round profiles, not necessary to change rolls.

\section{OPTIMIZATION OF ROLLERS}

\subsection{Modeling of rollers}

The design and optimization was performed using optimization techniques and CAD (Computer Aided Design) and CAE (Computer Aided Engineering) design and simulation using finite element method for the roll designed (Radulescu et al., 2006). Our was aimed to achieve a roll which will be used to withdraw the four dimensions of semi- finished round with diameters of Ø177mm, Ø250mm, Ø280mm and Ø350mm.

\subsection{Roller's design and modeling}

Solids body and drawing of withdrawing projects new rollers with multiple radiuses are identified in fig. 4 .

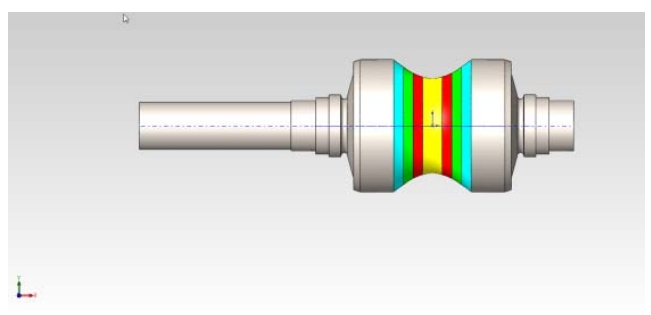

Fig. 4. Upper cylinder with multiple radiuses

\subsection{Simulation with FEM}

After the simulations performed by FEM (Finite Element Method), it is found that the ideal diameter machined on the roller, which is identical to that of blank withdrawal, because it provides maximum surface contact, between roller and blank. This gives a maximum tightening force on the rollers, good heat and exhaust to avoid strains on the blank. In fig.5 it shows the roller withdrawal processed with multiple radiuses, which may withdraw four types of performs without changing rollers. In fig. 5 is present the results of nonlinear dynamic simulation, which was realized used rollers with four radiuses, and the results of stress, strain and displacement.

It is found that by applying the same loads as in the case of cylinders with a single radius the critical values of stress, deformation and strain are not exceeded. This shows that the authors proposed solution is viable and can be applied in the withdrawal of the semi-finished at vertical continuous casting of steel with curvilinear wire.

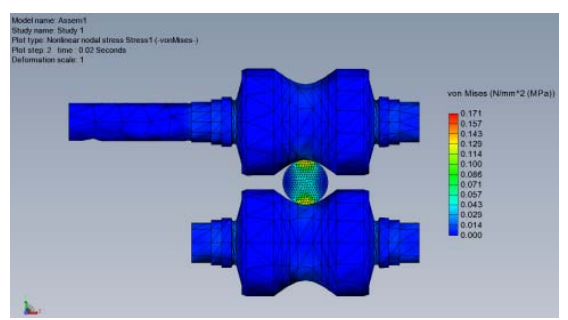

Fig. 5. Results for stress at the simulation

In fig. 5 are presented results for stress, at the simulation in case of withdrawal of a semi-manufactured $\varnothing 177 \mathrm{~mm}$ diameter. Note that the values do not exceed permissible values for the parameters studied and there are no major deformations of semi-finished products. Simulations carried out for semimanufactured with diameters of $\varnothing 177 \mathrm{~mm}, \varnothing 250 \mathrm{~mm}$ and $\varnothing 280 \mathrm{~mm}$ led to similar results commensurate with the diameter of semi-finished profile withdraw.

\section{CONCLUSIONS}

A pair of rollers with a single radius profile allows removal of a single round sizes, of the semi-finished and has the disadvantages.

By using multiple beams rollers authors proposed withdrawing all of the above disadvantages can be removed.

This implementation in semi-finished withdrawal process in continuous casting machines, multiple radiuses rollers contributes to:

1. Increase productivity-continuous casting of steel;

2. Material and labor-saving, necessary to build a set of rollers for each dimension of semi-manufactured products;

3. Reducing downtime required to change withdrawal rollers;

4. The possible withdrawal of blooms with multiple roll radius withdrawal;

5. Reducing the cost for continuous casting.

Future research will focus on the practical realization of these rollers and testing them on a continuous steel casting plant to validate the method proposed by the authors. Processing rollers will be carried out using CAM (Computer Aided Manufacturing) and CNC machine. Precision processing is required to ensure proper functioning of the rolls of withdrawal for semi-finished products of steel continuous casting.

\section{REFERENCES}

Marta, C., Numerical methods of simulation of casting and solidification of metal alloys, Eftimie Murgu Publishing House, Resita, 2005.

Radulescu, C.; Vela, I.; Varga, S.; Vela D., Projection of devices. Robotics, Didactic and Pedagogic Publisher, RA House, Bucuresti, 2006, ISBN 978-973-30-1635-9

Shapiro A. V., Gankin V. B., Smolyakov A. S., Shifrin I. N., Danilov V. L., and Zarubin S. V., Design of ContinuousCasting Machine and Estimation of Thermal Operation of the Solidification Zone, Steel in Translation, 2008, Vol. 38, No. 3, pp. 243-248. (C) Allerton Press, Inc., 2008

Tufoi, M.; Vela, I.; Marta, C.; Amariei D.; Mituletu C.; Stroia M.D., Design, optimization and realization of mechanical parts using CAD, CAE and CAM techniques, Annals of Daaam 2010, pp 421-422, ISSN 1726-9687

Tufoi, M.; Marta, C.; Vela, I.; Bizau, V.; Suciu, L., Method for the automation of horizontal continuous casting installation with programmable logical automata, Annals of Daaam 2009, 20, 01, 1611-1613, ISSN 1726-9687 